\title{
4 THE TYRANNY OF SPACE IN ORGANIZATIONAL ANALYSIS
}

\author{
Richard J. Boland, Jr. \\ Case Western Reserve University \\ U.S.A.
}

\begin{abstract}
We want to understand organizational process as the temporal making of meanings, but our vocabulary for doing so is predominantly spatial. Some mistakes this has led to in my own research are reviewed, and the hope for a more thoroughly temporal mode of analysis based on an actor' ongoing narrativization of experience is explored.
\end{abstract}

Keywords: Schema, frame, narrative, spacialization, temporal.

"We all secretly venerate the ideal of a language which in the last analysis would deliver us from language by delivering us to things."

(Merleau-Ponty, The Prose of the World,1973, p. 4)

\section{Introduction}

Our everyday, metaphorical use of space when discussing cognition seems to be harmless enough-helpful even. We use space as a metaphor in our thinking about thinking all the time, especially the metaphor of thinking as a journey in an enclosed space and the metaphor of an argument as a container (Lakoff and Johnson 1980). We speak, for instance, of our line of thought, our areas of interest, our field of study, or our domain of expertise. We also speak of thinking as taking place within problem spaces (Simon 1979,1996). Ideas are then objects in a problem space. We hold ideas, we entertain ideas, we examine ideas, we compare ideas, and we turn them over in our heads. In order for us to do this with ideas, of course, they must be available to us in our 
thinking in a very special way. They must be located or locatable within a space in order for us to be handling them, observing them, laying them side by side for comparison, or exchanging them in these ways. Taking ideas to be objects located in space and thinking of movement in a problem space is part of a larger process of using spatial imagery to understand our temporal experience as conscious agents (Bergson 1911, 1920).

In this paper, I discuss some implications of the familiar and everyday ways in which we spatialize our discussion of thinking and ideas - of the way we use spatial imagery to "get a handle on" the thinking of managers - in order to point out some of the undesirable consequences which I believe are not so familiar. This paper began with a series of uneasy feelings that developed over many years in doing my research on information use and information design in organizations. For a number of years, I was doing research that kept "backfiring" because the images of space that were implicitly guiding it didn't seem to yield the expected results. Lately, I have begun to find a vocabulary for discussing this sense of unease as having to do with the almost exclusive use of spatial metaphors and the need for more temporal and processual ones. I have also found a possible antidote for the excessive reliance on spacial imagery and the way it encourages an understanding of cognition as information processing in Jerome Bruner's $(1986,1990)$ more temporally sensitive work on narrative modes of cognition.

I will present my argument by recounting the process I myself went through in trying to make sense of information design and use in organizations. In overview, I will argue that our use of terms such as frames, schemas and paradigms is in many ways misleading. They all are derived from the practice of spatializing our thinking about thinking. They suggest the existence of bounded spaces that reside in the minds of organization members which contain identifiable constructs and their interrelations. They lead us to think of problems in organizations as often being created by an absence of sufficient "shared knowledge," "shared understanding" or "shared meaning." They lead us to propose that the creation of such "shared" cognitions will provide a solution to many organizational problems. Phrases such as "shared understanding" are particularly potent examples of the way we spatialize cognition. I assume that in order for understandings to be shared, we must first allow that an individual's cognition is composed of discrete concepts or idea units and that they are located in a cognitive space that is homogeneous or sufficiently compatible with the cognitive space of other individuals such that they can be compared and found to be matching. I see no reason to take this seriously, yet we continue to see in organization studies that success or failure in organizations is attributed to the presence or absence of "shared meaning."

\section{Some Studies of Frames, Framing, Reframing, and Frame Shifting}

I will organize my argument by telling the story of my own journey through the world of organizational research. It is a tale of lost beginnings, a tale of studies conducted to search for answers to questions that were in the end called into question themselves. It all began in 1973 with an interest in the "problem of implementation" in operations research and management science. Very clever and seemingly helpful decision making tools were being developed in response to management requests for assistance from operations research and management science, but managers weren't using them. 
Similarly, vast sums were being spent on the development of computer-based information systems, again, at the request of management, but in the end these systems were failing to be completed or used as intended. One popular way of posing this problem was provided by Churchman and Schainblatt (1965), who described it as a problem of failing to achieve "mutual understanding" between computer system analysts and the intended users of these systems. I began working on this "problem of implementation" and the search for mutual understanding by drawing on some notions from organization development and trying to create patterns of interaction between analysts and users that would tend to develop systems better attuned to management needs.

In that first study (Boland 1978), I began with the idea that system users and system analysts had different schemas or frames and the problem of implementation had to do with one frame dominating over the other (Argyris 1971), thus reflecting a lack of mutual understanding in the resulting system design. I focused on a key step in system design: the identification of information requirements, or the data that the new system was expected to produce either on a recurring basis in the form of standard reports, or on an ad hoc basis in response to a manager's special request. I characterized the traditional technique of system development as being led by the system analyst, and documented the best practices for interacting with users that were suggested by system analysis textbooks. These practices were then formalized as a set of protocols to be used by the analyst for interacting with the user. These protocols included guides for asking good questions, analyzing data, and developing a model of the user, the organization and their information requirements. I anticipated this would take place within the schema or frame of the analyst.

As an alternative to this, I used some techniques loosely adapted from organization development to create a set of protocols for interaction that would induce a team approach in which both the analysts and the users schemas or frames were involved equally in determining the information requirements. In this protocol, no one asked questions - instead, they both revealed things about their values, ideals and experiences to each other, then jumped to conclusions about what the computer system should be like, then critiqued each others' suggestions. I tested the two sets of protocols by having system analysts from industry and nurses from surgical floors of a hospital work in pairs to define the nurses' information requirements.

I anticipated, among other things, that the alternative protocols would result in greater mutual understanding, with each team member being better able to adopt the schema or frame of the other. As a result, I expected that the teams using the alternative protocols would develop better information requirements, as judged by a panel of nursing experts. The results confirmed these expectations. But in analyzing the designs that the different analysts had proposed, I was struck by the realization that they had all, in a sense, done equally well in solving the design problem that they had posed for themselves, but they had posed different problems to solve. Also, the panel of nursing experts was just one possible way of scoring these results. Other judges, such as finance directors or doctors, might have scored them much differently. What was it that made the nurses' frame the correct one for scoring these ideas? The analysts showed a variety of ways of framing the nurses' problem, each one led them to a different statement of the problem they were to design a solution for. This realization awoke in me an awareness that what had been going on was not so much a problem solving exercise as a problem 
framing exercise. The protocols didn't so much affect the ability to solve the nurses' problem as it affected the way the nurses' situation was turned into a problem. So it was not the problem solving performance that was being mediated by these different interaction protocols so much as it was the problem framing performance.

This led me to an exploration of the social construction of reality (Berger and Luckman 1967), symbolic interactionism (Blumer 1969), anthropological studies of symbolism (Sperber 1974), and a concern with biases from attribution theory (Kelley 1973) in which observers see others as facing situations that were more understandable, more certain and more subject to their control than the actors themselves did in those situations (Boland 1979). At the time, I was at the University of Illinois at UrbanaChampaign and privileged to be working with Lou Pondy. He and I did two studies together in which we explored problem framing in the context of accounting and budgeting. In the first study (Boland and Pondy 1983), we used Scott's (1981) distinction between "rational" and "natural" system models of organizing to explore budget cutting in two case studies. Rational system models "assume managements are confronted with an objectively knowable, empirically verifiable reality that presents demands for action" (Boland and Pondy 1983, p. 223). Using these models, managers assess cause effect relations and take action based on the demands of the situation. Natural system models, in contrast,

see managements as responsible agents who interact symbolically and, in so doing, create their social reality and give meaning to their ongoing stream of experience. Problems are not simply presented to managements, problems are constructed by them. [Boland and Pondy 1983, p. 223]

Lou coined the phrase "Genuine Union" for the way we saw both the rational and natural models being used by managers in an alternating sequence of figure/ground relations. We were eager to argue against contingency theory and propose that both models were always in use, one always providing the background as the other was brought to center stage. It was not a contingent either-or but a genuine union both-and. In the budget cutting meetings we studied, we read managers dialogue as being within one model for a while, but then switching to the other and reversing their figure/ground relation.

In the second study, we analyzed the transcripts from a budget cutting meeting in a public school district that Lou had been studying (Boland and Pondy 1986). In making our interpretation of those transcripts, we used a coding system in which we recognized distinct modes and models of cognition and coded the dialogue based on the modemodel combination that was evident. For the modes, we used "instrumental" and "symbolic" modes of cognition (derived from Scott's rational and natural models), and we added the four decision models (fiscal, clinical, strategic and political) identified by Meyer (1984) in his study of hospital decision processes. Once again, we identified a series of switches among mode/model combinations, as shown in Figure 1 for the discussion of a budget line item. This strengthened our belief in the idea of a "Genuine Union" between instrumental and symbolic modes of thought, and of the importance of figure/ground reversals between them during decision dialogue. We also came to see the importance of shifting among decision models as well. The decision dialogue seemed to be taking place through a series of conversational transitions, so that knowledge 


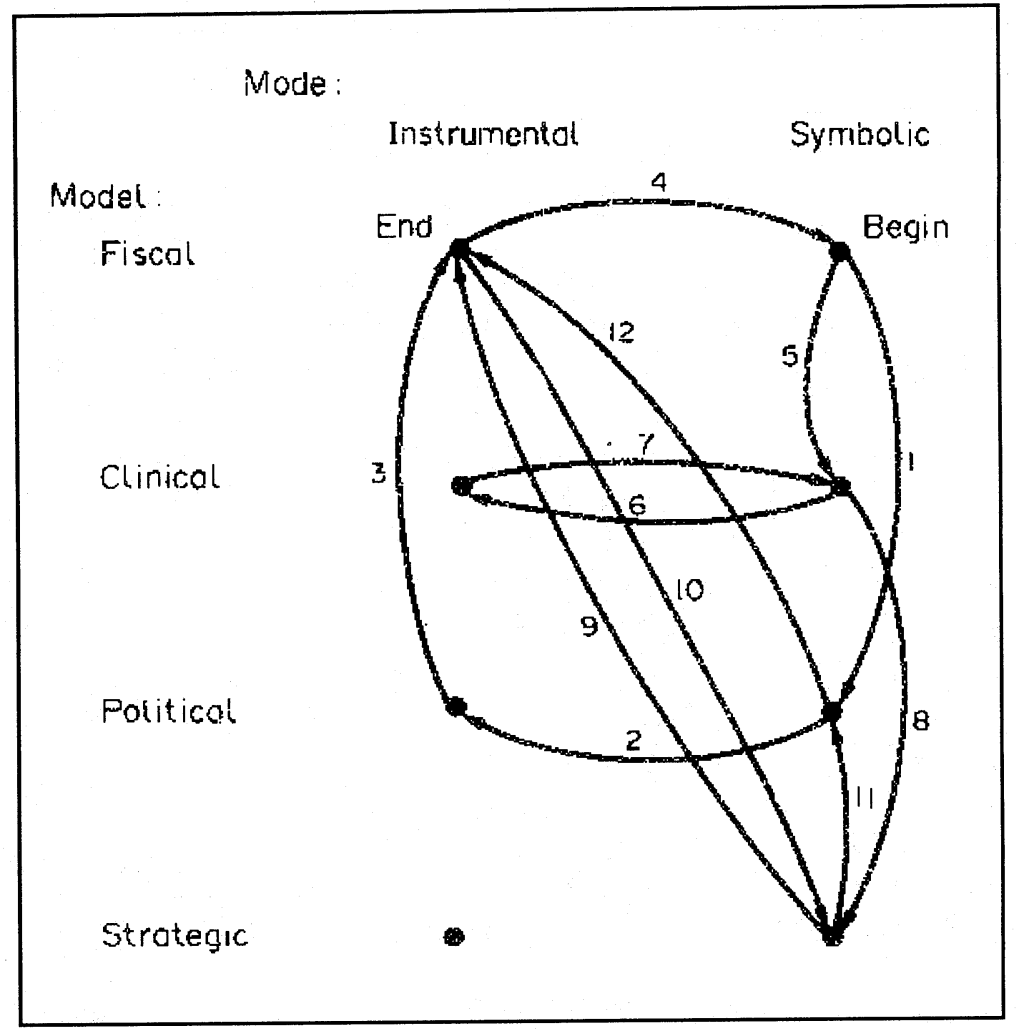

Figure 1. Map of Topic 1, "Athletic Budget," 561 Lines

creation was a journey moved forward by shifting among mode-model combinations through a series of conversational transitions. Participants seemed to carry meaning making through the transitions, and experience the discussion as continuous in the face of its continuous transition.

So far, the work I have reported had been a kind of strange dancing with frames. It started with a naive sense that different frames were held by different kinds of experts and the hope that different patterns of interaction could somehow meld them together as opposed to letting one of them dominate. It developed into an awareness of problem framing and the symbolic action of individuals in giving meaning to situations, as they actively frame them. From there, it evolved into an appreciation of the multiple frames available to actors and the process of working within frames versus working between frames. From there, we added the process of dynamically shifting among frames during conversation - with a figure/ground image of this shifting-as being important for understanding how group decision processes work. But all the time, the notion of a frame or a schema was there as an assumption. Whether the actor is assumed to be within a frame, in the act of framing, or shifting among frames, the idea of frame was still there. In retrospect, I am reminded of the exasperation revealed in Philosophical 
Investigations when Wittgenstein looked back on his "picture theory" ideas from the Tractatus:

103...Where does this idea come from? It is like a pair of glasses on our nose through which we see whatever we look at. It never occurs to us to take them off.

Shortly after this work with Lou Pondy, I continued exploring frames with Ralph Greenberg, another colleague at Illinois. We looked at the role that metaphors might play in the problem framing process by inducing subjects to interpret a situation using either a mechanistic or an organic metaphor (Boland and Greenberg 1992). We induced the metaphors by first getting groups of subjects to identify examples either of machines (mechanistic) or of plants or animals (organic) using a nominal group technique to generate a list of examples. Then, we asked them to identify adjectives and adverbs that characterized the qualities of items on the list. Finally, we asked them to analyze an organizational case study, and to begin their analysis by naming the situation (as a machine or as a plant or animal) with the phrase "This situation is like a and in their analysis to use whatever images from the generated lists of adjectives and adverbs that they thought best represented the situation.

Our intention was to test whether a mechanistic versus organic metaphorical framing would result in different problem formulations. We were, of course, confident that it would since the power of a metaphor to frame a situation in a particular way (Schon 1979) and the use of organism versus mechanism had been so widely accepted in organization studies (Morgan 1986). Instead, we found that subjects continually surprised us with their ability to use either type of metaphorical framing to describe the case situation as being almost any kind of problem. Subjects could declare the organization to be too centralized or too decentralized, too rigid or too flexible, and could propose corrective restructurings based on those problem formulations, regardless of the metaphorical imagery they employed in their problem framing.

You would think at this point that we would give up on the idea of a frame as a cognitive construct with much power. Instead, we marveled at the human ability to play "language games" and were inspired "by Wittgenstein's enduring insight into the multiplicity of the uses and meanings we humans make with the most familiar of words.

11. Think of the tools in a tool-box: there is a hammer, pliers, a saw, a screw-driver, a rule, a glue-pot, glue, nails and screws.-The function of words are as diverse as the functions of these objects.

Greenberg and I were not about to give up on the idea of reframing, though. If metaphors wouldn't reveal it, then perhaps being confronted with out of frame data would. We picked up and completed a project that I had begun with another colleague, Soong Park, a few years before (Boland, Greenberg, Park and Han 1990), in which subjects first analyzed a case study, then identified the alternative courses of action open to management and made a request for the data they would need in order to choose which alternative to recommend. Our manipulation was to either give the subjects the data they had requested or to give them data that had been requested by someone else, who was deciding between different alternative courses of action. Our expectation was 
that subjects who received the data they had requested would continue to operate within the problem frame they had initially developed, and would choose a course of action to recommend from among the original set they had identified. Subjects who received data they had not requested (data that was relevant to other ways of framing the problem) would tend to ask themselves the questions that the data helped to answer. We anticipated that they would be more likely to change problem frames and select a final course of action to recommend that was not one of the original ones they had identified. Once again, we were surprised by the results. Subjects who received data that was relevant to other ways of framing the problem clung tenaciously to the alternatives from their original problem definition, and selected one of those alternatives as their final recommendation. On the other hand, subjects who received the data they requested in order to choose among the alternatives they had identified frequently changed their problem frame and recommended a final course of action that was not in their original set of alternatives.

You would think that now we would start to give up on frame and try some other way of thinking about what is going on in peoples minds when they are thinking about organizational problems. But the idea of frame is just too powerful and obvious to give up. We kept interpreting these results as variations on the theme of framing, and argued that the results emphasized the creative, constructionist power people have to frame and reframe in the most surprising ways.

\section{Map Making, Interpreting Numbers, and an Awareness of Narrative}

Apart from these studies that were directly on the theme of framing, most of the work I have been involved in through the years has touched on related topics of sensemaking and interpretation (Boland 1984). I'll mention two of them here. One stream of work has to do with cognitive mapping. Ram Tenkasi, Dov Te'eni and I worked with new product development teams from DEC on the problem of reducing the "disconnects" that they were experiencing (Boland, Tenkasi and Te'eni 1994). Disconnects were when a new product came out and its consequences had not been adequately foreseen by various parts of the organization: the sales force had anticipated its uses or functionality to customers incorrectly, or the manufacturing facilities were inadequate, or the marketing plan didn't allow for key customer groups, or the financial projections were too high or too low. The project was to develop a cognitive mapping tool that would enable actors from different parts of the organization involved in the new product introduction to create, exchange and critique cognitive maps of their individual understandings of what the causes of success or failure of the new product were going to be. Our idea was that the problem of disconnects was at least in part a communication problem, and the different actors on these new product introduction teams each had different ways of framing their understanding of customer needs, alternatives in the market, moves by their competitors and so on. If they could each make the understandings from their different frames visible, we thought, they could develop better mutual understanding, be better able to take each others' frames of understanding into account and be able to reduce the number and scope of "disconnects" (Boland, Schwartz and Tenkasi 1992; Te'eni, Schwartz and Boland 1992). 
We happened, unfortunately, to be working with DEC at the time of a great internal transition for them. The founder and CEO, Ken Olson, stepped aside, and a new management team and a more hierarchical style was put in place. The new product introduction process was changed drastically, and a comparison of before and after with the cause mapping communication process was not possible. Still, we did spend many months making and exchanging maps among the team members, and the results from that process and other mapping projects did teach us something about frames, maps and communication. We had begun the project with the idea that people did have frames and fairly well developed understandings of their areas of expertise. What we found was that individuals would start to make a cause map by putting a few factors and relationships into the map, and then stop. We had expected that people would be using the map as a way of recording their causal understandings, and worked on ways that the software tool would enable them to record them easily and flexibly, with rich linkages from elements in the map to underlying evidence and supporting data. Instead, we found that people didn't have much in the way of well developed understandings to put into the map in the first place. Making the map, in fact, almost seemed to be an opportunity to think about the causal relations as if for the first time. It was an opportunity for creative thinking that was invariably marked with expressions of discovery such as "Isn't this interesting," and "Look what's developing here." So instead of cause maps being a process of documentation of frames and exchange of understandings, they were a process of invention of frames in the first place and an almost naive exploration of these new found frames and their possible meanings.

This was probably the first dawning of the realization that perhaps the whole idea of people having "frames" was misguided. Frames, problem spaces, schemas all seemed so much harder to believe once you started working with people making maps of their area of expertise. They didn't seem to have a frame to simply report or document, but they could construct one and the experience of doing so was exciting and novel for them. So what was going on? What would it be like to do research of this sort that was openly "frameless"?

At about this same time, I began analyzing some data that had been collected by Ron Milne during his Ph.D. thesis, but not used by him (Milne 1981). He was interested in studying the effect of extrinsic versus intrinsic motivations on decision making in different budgeting contexts. Using a lab experiment, he had managers make choices about which of two managers to promote. In one condition, the managers had only actual accounting results for each manager's performance over the past three years. In the other condition, subjects had both actual and budget figures. Subjects had to chose which manager to promote, based on the accounting reports only, and were told that the candidates were equal on other, more personal dimensions. During his experiment, Milne had asked each subject for the reasons why they had chosen the manager they were recommending for promotion, but had not used that data in his analysis. I took that data and interpreted how those managers had interpreted the accounting reports in the two conditions (Boland 1993). I expected that the ways of making meaning with the reports would be different under the two conditions, and to an extent there were differences, but once again, my "real" finding was something unexpected. I argued that managers in both conditions made the accounting reports meaningful by using the numbers to bring the people behind them to life, endowing them with personalities, intentions, and histories, and animating their behavior in a hypothetical situation. Once 


\section{Table 1. Reasons for Promotion Choice}

\section{Reader A: no budget, choosing East \\ East appears to be innovative and resourceful. I would like the company to grow and I feel that East would be more likely to facilitate that end result. He more than achieved double the extra activities without doubling the cost. He takes risks within his department but they appear calculated to achieve outstanding results.}

\section{Reader C: budget, choosing East}

The most important selection criteria was activities performed in addition to the standard 57. Typically, home office personnel departments get the tough problems bumped up from below. A good manager must be able to juggle a lot. Such a quantity of extra activities may indicate East is operating out of his department's scope-but it also indicates East is much more of a "gogetter" than West.

The expense data also indicated East was more aggressiveobtaining higher salaries and more equipment than West. Since such expenditures are normally approved by higher headquarters, East clearly has a pipeline to the right ears.

Least meaningful was the performance on the standard 57 activities. East is steadily doing better, but West has been consistently good. No other data was relevant. But personality and management style is very important for such a position.

\section{Reader D: no budget, choosing West}

I picked the "West" manager because he ran a tighter ship as far as budget was concerned and seemed to be more time organized. If he used the amount of money "East" did he would definitely have better results. Both had approximately the same number of employees but salaries were very different. "West" didn't spend an inordinate amount of time on activities other than the required since it is wasteful given the fact there is little direction as to what is important.

again, the way subjects were able to animate the people behind the numbers did not seem bound by the accounting results, or the presence or absence of a comparison to budget. They seemed to have a very potent interpretive capability, and could read the numbers as being good or bad as it pleased them. I positioned the analysis as a counterpoint to 
work in accounting which attributed a strong, common set of meanings to accounting reports (Macintosh and Scapens 1990).

Three examples of such differences in interpretation are shown in Table 1. Two things stand out relative to the purpose of this paper. First, the interpretation they make is dependent on the type of person they understand the manager to be, including the intentions, motivations, social skills, and personality they attribute to the manager. Second, they bring the person behind the numbers to life through the use of metaphor, but the metaphor is really a side issue compared to the way they narrativize the situation and the manager's behavior in it. The metaphor of a ship captain, an over achiever, or a juggler that they use is more of a "seed" for the telling of a story than a frame used for analysis. It was the motivated; intentional actor in a setting-facing a situation with a history and engaged in action with others who had their own interests- that was the medium of interpretation. It was the narrative that they constructed that propelled their reading and gave it meaning. And they were able to construct rich and diverse narratives from the scantiest of materials: columns of accounting numbers for department performance over the past three years. The bare numbers were enough for them to infer the kind of human agents and social setting that would produce such numbers, animate those agents in interaction with others, and "see what happened." It wasn't a schema or a frame which was at work, it was a story line that made the numbers sensible and the promotion choice inevitable.

The inspiration for taking narrative seriously, and for pushing the notion of frames aside, came from reading Jerome Bruner $(1986,1990)$. Early in his career he had been deeply involved in establishing the "information processing" school of cognitive psychology, and now he was arguing against the way that it had become a dominant, paradigmatic view of cognition. He was arguing that the information processing view was suppressing another, more frequently experienced mode of cognition that he was calling the narrative mode. In the information processing mode of cognition, we assess probabilities, we test hypotheses, we deduce consequences, and follow a pattern of "if $x$, then y" kind of thinking. In the narrative mode of cognition, we tell a story in which actors with causal powers enact a sequence of events, and follow a pattern of "first $x$ happened and then y happened and then $\mathrm{z}$ happened" kind of thinking.

Through the information processing mode of cognition, we can show that we are right by demonstrating the logic of how our conclusions follow from our premises. In the narrative mode, we show we are right because the story is plausible and believable. The power of the story is in explaining why things are the way they are, and who we are as persons in a way that rings true to our experience and culture. In the information processing mode, the logic of our argument is supplied by the author and is apparent on the surface. In the narrative mode, the plot that ties the sequence of events together is supplied by the reader or hearer of the narrative as they subjunctivize its meaning for themselves.

The narrative mode of cognition and its portrayal of our situation as a plausible sequence of events is our principle way of making sense of our ongoing stream of experience. With it, we narrativize our life and its meaning to ourselves and others in real time as well as retrospectively and prospectively. Through narrative, we construct the identity of self and other as moral agents, assert what is true about our culture, repair apparent breeches in the canonicality of culture, and construct the conditions of our own action. If there is something like a frame or problem space within which the information 
processing mode of cognition operates, it is created through narrative. But somehow, narrative as a mode of cognition is consistently undervalued.

To take one instance of how, as Bruner argues, the information processing mode of cognition is given a predominant position in our world and of how the narrative mode is suppressed, consider Carol Gilligan's (1982) example of two children being tested with Kohlberg's hierarchy of moral values instrument. Jake and Amy are both 11 years old. As part of Kohlberg's standard test, they are told that Heinz has a wife who is dying and he cannot afford the drugs required to save her life. They are asked, "Should Heinz steal the drug?"

Jake resolved the problem by bringing it within a hierarchy of rights and responsibilities which enable him to use deductive logic. He said Heinz should steal the drug because a human life is more important than property. He in effect turned the problem into a simple kind of calculation, reflecting use of the paradigmatic or information processing mode of cognition, and he scored well on Kohlberg's instrument (between a three and four on Kohlberg's six stage scale).

Amy, on the other hand was unsure what Heinz should do. She tried to animate the situation and explore new possibilities:

I think there might be another way besides stealing it, like if he should borrow the money or make a loan or something, but he really should not steal the drug. [p. 28]

When asked why he shouldn't steal the drug, she didn't use a calculation within a hierarchy of values, but continued narrativizing other possibilities for the unfolding situation:

If he stole the drug he might save his wife then, but if he did he might have to go to jail, and then his wife might get sicker again, and he couldn" get more of the drug. [p. 28]

As Gilligan put it, Amy saw "in the dilemma not a math problem with humans but a narrative of relationships that extend over time" (p. 28). Amy did not employ the information processing mode of cognition to deal with Kohlberg's paradigmatically inspired theory, but instead employed a narrative mode to try and rewrite the story. The interviewer continued to ask her for an answer. Her stories were not codeable in Kohlberg's instrument. Eventually, Amy gave up and said simply that Heinz should not steal the drug "because it's not right." She then fit Kohlberg's scale and was scored between two and three, putting her below Jake in her moral reasoning.

Earlier, I had recounted Lou Pondy and I exploring the "symbolic" versus the "instrumental" mode of analysis. At that time, too, we saw the symbolic mode being devalued and pushed aside by the instrumental mode in organizational studies. Rather than retaliating by trying to deny the importance of the instrumental mode, we proposed that they formed a genuine union as an individual alternated back and forth between them, and that the symbolic mode played a role in framing and reframing the problem space used by the "instrumental" mode. Now, an awareness of narrative as a mode of cognition complicates that image. Bruner's information processing mode seems to match what we had in mind as instrumental forms of thinking, but I don't want to say 
that narrative is just a substitute for what we meant when we used the term symbolic, although clearly there is a connection of some kind. Eventually, I would like to explore how the narrative and the information processing modes of cognition form a genuine union, but in this paper, I would like to focus on how these different modes are being informed at a deep level by our basic concepts of space and time. I will propose that the information processing mode takes an inherently spatial approach to cognizing situations, and that the narrative mode takes an inherently temporal approach. As in the genuine union model, both are needed, but one dimension, the spatial dimension, has dominated and suppressed the temporal dimension. But first, let me give one example of a study of the narrative and information processing modes of cognition that I undertook with Ulrike Schultze (Boland and Schultze 1996), and then come back to this question.

During her study of the effects of information overload in computer mediated environments, Schultze collected examples of decision dialogues that took place in a Lotus Notes system at a large insurance company. The decision setting was a project called "Product Alignment" in which managers from around the United States were standardizing their rules for writing and pricing auto insurance policies. Below I will discuss some messages from that Product Alignment database:

\section{Message 1:}

\section{Rule Number: 4 \\ Key Person: S.A. \\ Rule Description: Driver assignment / FINAL}

Policy premium is determined by assigning the highest rated driver to the highest rated vehicle, second highest driver to the second higher vehicle and so on. The highest rated driver refers to the operator whose age, sex, marital status and surcharges develop the highest premium. If there are more vehicles than drivers, rate each additional vehicle using a default class $\mathrm{XX}$, where rates are based on the lowest rated liability driver class available on the policy with zero points.

\section{Message 2:}

Author: E.C.

Date: 09/08/93 09:44 AM

Comments at Sept 8 - 9 Evaluation

clarify rule to indicate that the lowest rated driver class on the policy (for liability) will be the one used for the default driver class, group agrees to use default driver class code XX.

These two messages come at the end of an extended process of discussions about rule 4 , concerning the assignment of drivers to policies for pricing purposes. The first 
message gives a concise statement of the rule that the author sees as having emerged from their discussions. It is a strong information processing mode statement, and conforms to the image of cognition as movement through a problem space. Drivers, vehicles and their category descriptors are arrayed in the problem space and assignment is a logic for moving through the space: if $\mathrm{X}$, then $\mathrm{Y}$, else $\mathrm{Z}$. In the second message, this mode is again evident as a sharpening of the categories that gives precision to the use of "default driver class." Both these messages have short, staccato phrasings, are assertive in tone, and use an abstract voice. They are intended to close the deliberations on this rule and depict it as a well formed problem space to be used by others. But in the next message of this data base we see the narrative mode of cognition used to reopen the search for meaning in their deliberations:

\section{Message 3:}

Author: R.C.

Date: 09/13/93 01:15 PM

\section{Highest to highest, Not}

Our rules say highest driver to highest vehicle, but what we calculate is highest total premium for the policy. These two can be different, here's an example:

2 cars, 2 drivers.

1 young driver with a bad record.

1 mid-aged driver (say a widowed woman) with a good record.

One car with liability only, symbol 80 .

One car with full coverage, symbol 60.

Assume symbol 80 has slightly higher factors (for liability).

In this care "highest to highest" would probably put the kid on the symbol 80 vehicle. We all know the highest policy premium occurs when the kid is on the full coverage vehicle, which is the way we do it.

Over the years we've come to understand highest-to-highest as meaning the "highest total premium for a policy by aligning drivers and vehicles."

Message three disturbs the hoped for closure of rule 4 by using the narrative mode of cognition. The story, told in outline with a mocking introduction undermines the logic of the Final Rule by introducing characters that "we all know," putting them in action in a plausible scenario, and drawing a moral. We as readers subjunctivize the few narrative elements that are provided into a story. The author does not mention the sex of the "kid", but we know it's a male - and we can see him with a baseball cap turned backwards and the radio blaring as he drives too fast. We also know the female character. She is dressed modestly, talks in a soft voice and wears sensible shoes. "We all know" these characters and "we all know what we do" when we rate them. The narrative draws its power from the sense of canonicality and culture that it both draws upon and creates at the same time. The message is saying that our practices for dealing 
with these kinds of non-canonical situations and repairing the moral basis of our culture are who we are as a company. Narrating the rule in action in this way transforms it from a question of logic to a question of identity and assertion of self. The moral of the story is not stated explicitly, being left for the reader to complete as part of their interpretation. But importantly, this message has opened the issue for further discussion. What the information processing has closed down, the narrative mode has opened up.

\section{Message 4:}

Author: C.C.

Date: 09/16/93 12:08PM

\section{Consistency}

How we can have a "final" rule that does not conform to our practice? Are we affirming the rule and planning to change our alignment algorithm; or have we decided to file the rule and await a market conduct audit to demonstrate that we are not conforming to our filed rules?

Message four responds to the invitation of message three and extends the narrative mode. The author is moved by the story of message three and is exploring the apparent ethical dilemma presented by the rule as an expression of the identity of the firm. The author explores several paths the story could follow, and using an impartial narrative voice, opens the possibility for the reader to state a moral position: when rule and practice do not fit together in a coherent story, how do we proceed? Who are we and who will be if we live the story this way? What other story lines are open to us? These are some of the ways that the narrative mode of cognition can open new possibilities for action and create new opportunities for reflecting on the identity and culture of an organization.

\section{The Spatialization of Thought and Experience}

In this section, I want to explore some of the possible reasons and implications for the endurance of notions such as frame, schema or mental model. In my own experience of doing research, these notions have been prominent in both the construction and interpretation of studies. Yet, as I have tried to argue above, they don't seem to be supported by the results. This did not stop me from presuming the notions, using them, or acting in the name of them. And it doesn't seem to stop others either. The notion of frame or schema is something we just take for granted. In fact, it appears that Piaget is one of the few scholars to have done extended work on the creation and change of schemas over time, and even he didn't try to test the idea of schema itself. So where does the notion of frame or schema get its power and durability?

To begin with, the notion of frame or schema has roots that are very old and recurring in philosophy. Plato, as we know, argued that knowledge was based on ideal forms which are resident in the mind a priori. Particular ideas or experiences are understood as imperfect versions of the ideal forms already in the mind. Learning 
becomes a process of remembrance. In the dialogue with Meno, we see that geometry is known to the servant even without any formal education, if he is properly guided in the remembrance process. Aristotle, in contrast, argued that knowledge came from sensation and experience. Ideas were not ideal forms already in the mind but were the result of a process of stripping away inessential details from sensations, leaving abstract ideas. These two poles of the debate about human cognition seem to have been set very long ago, but either way, ideas such as frame and schema should have a ready place in our way of understanding cognition, because both shared the assumption of knowledge as an image in the mind.

In the enlightenment we again see these two poles. John Locke (1975) argued against the notion of a priori forms in the mind, emphasizing experience and sensation as the sources of all knowledge. The mind was a tabula rasa upon which the primary qualities of sense experience were recorded as simple ideas. The mind, in turn, built simple ideas into complex ones through the process of self reflection. As part of his argument against a priori forms, Locke pointed to the obvious lack of consensus on basic principles of political and economic organization. In contrast, Locke's contemporary, Gottfried Leibniz, argued for the necessity of innate ideas and a priori forms. But once again, both poles of the debate assumed that human understanding was based on an image.

Kant strengthened this image-based tradition when he drew in part on Leibniz and argued that we could know the world to the extent that it corresponded to the structure of mind, as we imposed a priori schemas to form images on the manifold of experience. Such schemas were forms of sensibility, lying ready in the mind.

The schema of sensible concepts...is a product and, as it were, a monogram, of pure a priori imagination, through which, and in accordance with which, images themselves first become possible. [Kant 1965, A141-142 = B 181]

For Kant, the principle schemas were space and time, and of those, time was only understood by us when we could relate it to space. In his Inaugural Dissertation of 1770, he argued:

The formal principles of the phenomenal universe which are absolutely primary, universal and at the same time the schemata and conditions of anything else in human sensuous cognition, are two, namely, time and space. [Kang 1985, p. 66]

Space is employed as the type (analogy) even of the concept of time itself, representing it by a line and its limits-moments-by points. [Kang 1985, p. 67]

It's important to remember, though, that a schema for Kant was a constructive process.

The schema is in itself always a product of imagination. Since, however, the synthesis of imagination aims at no special intuition, but 
only at unity in the determination of sensibility, the schema has to be distinguished from the image. [Kant 1965, A140 = B179]

Yet, it appears that the idea of schema or frame, to the extent that it is derived from Kant, has come down to us in organization studies as a rather rigid, complete and well formed image, rather than as the sensibility or the imaginatively constructed form that he had intended.

Bartlett, who is most frequently seen as the direct source of most uses of schema and frame in cognitive and organization studies today, appears to have suffered from the same hardening of the construct at the hands of his contemporaries. Bartlett, in his classic Remembering: A Study in Experimental and Social Psychology, complains about the use made of his construct of schema:

I strongly dislike the term "schema".... It suggests some persistent, but fragmentary, "form of arrangement," and it does not indicate what is very essential to the whole notion, that the organized mass results of past changes in position and posture are actively doing something all the time....It would probably be best to speak of "active, developing patterns"; but the word "pattern," too, being now very widely employed, has its own difficulties; and it, like "schema," suggests a greater articulation of detail than is normally found. I think probably the term "organized setting" approximates most closely and clearly the notion required. [Bartlett 1932, p. 200-201]

Later, reflecting on the difficulty of using the word schema to express his experimental findings that remembering was an active construction, he concludes:

It may be that what then emerges is an attitude toward the massed effects of a series of past reactions. Remembering is a constructive justification of this attitude; and because all that goes to the building of a "schema" has a chronological as well as a qualitative significance, what is remembered has its temporal mark; while the fact that it is operating with a diverse, organized mass, and not with single undiversified events or units, gives to remembering its inevitable associative character. [Bartlett 1932, p. 208]

Herbert Simon $(1979,1996)$ is perhaps the most well known exponent of the role of a "problem space" in framing human problem solving. For Simon, the problem space is always temporary, incomplete, and subject to revision, but none the less necessary. In the problem space, there are nodes. Each node is an element of the problem or of a possible solution. Problem solving is a movement through the problem space from the current node to other, as yet unvisited nodes to test if they are taking the problem solver closer to or further away from the solution or goal.

How is it that the schema or frame that has been handed down to us for so very long, with each individual who is about to hand it off to us pleading for us to recognize the inadequacy of the term, ends up being treated by us as if it were stable, well formed, boundedly rational, coherent and suitable for navigation? Simon himself repeatedly 
warns us that the problem space which results from any particular naming of the situation, or problem representation, is always inadequate-yet he proceeds to assume the existence of a well formed problem space and to conceive of problem solving as operating within it.

What is important to remember, I think, is that it is the temporal process of cognition in decision making or problem solving that is being modeled with the vocabulary of schemas and frames and problem spaces. Why is that? Why is the temporal experience being represented and modeled with spacial concepts? And does it make any difference? To me, the examples of the information processing mode that we saw before in the Lotus Notes messages is important to remember. It was used to shut the inquiry off, to close the problem space and end the discussion. The more temporally based narrative mode, on the other hand, was used to keep the question open and to keep the dialogue going. There must be a tradeoff between the opening and closing of inquiry, in which some balance between opening and closing is deemed most appropriate. But to the extent that spatial imagery and its associated information processing modes of cognition are treated as the only "real" cognitive account of problem solving, that balance is sure to be too heavily weighted toward the closing off of inquiry and dialogue. Which seems to be just the point when we complain about organizations not learning from errors, not being able to unlearn in the face of changing circumstances, and so on.

Henri Bergson $(1911,1920)$ had a very nice way of diagnosing this condition in which we seem to favor the spatial over the temporal in cognition. He makes a clear distinction between the way we can know the experience of time, and the way we can know objects in the extensible world. Objects can be measured and for practical (but ultimately arbitrary) reasons can be treated as separate or separable from other objects in their environment. Time, however, cannot be so measured because it is not made up of isolatable pieces and thus cannot be known by the same type of intelligence that knows objects. Time, he argued, is experienced as a duration in which there is no isolatable instant of "now." There is instead an ongoing experience of past, present and future interpenetrating each other as a continuous, seamless whole. Consider, as he does, the movement of your arm sweeping before you in space. As Kant had suggested, it can be known as a series of points in space only if we first imagine the trajectory it travels, and then, recounting the way the arm travelled through that trajectory, pretend that the experience of movement was like the line we have drawn in space. Like the line, our experience of movement, it is supposed, can be broken into separate pieces and measured in isolation as points in space (Bergson 1911, pp. 248-249, 290). But the experience of motion as a temporal duration has no such separate moments. It is an indivisible, undivided whole.

Bergson sees this same kind of confusion at work when we discuss the information processing view of cognition and describe the human problem solver as navigating a problem space following a branching model of problem solving. Temporally, the experience is like the movement of one's arm in that it is an undivided whole with each instant being an interpenetration of past, present and future. To talk of navigating problem spaces and following a path through nodes toward a goal is only possible in retrospect. In phrases presaging Weick (1979), Bergson critiques the spatial journey like description of cognition: 
Of course, when once the road has been traveled, we can glance over it, mark its direction, note this in psychological terms, and speak as if there had been pursuit of an end. Thus shall we speak to ourselves. But, the human mind could have nothing to say of the road which was going to be traveled, for the road has been created pari passu with the act of traveling over it, being nothing but the direction of this act itself. [Bergson 1920, p. 54]

\section{Conclusions and Discussion}

I have argued that the spacialization of knowledge and of our thinking about thinking is a problem in that it tends to close off inquiry, to trap us into taking words like schema and frame too seriously, and to lose sight of the temporal experience of meaning making. It would be nice to be able to point to some simple remedy, but none seems available. The dominance of space is ubiquitous in our language, in our day to day practices and in our historically constructed ways of understanding cognition and organizations: It is a tradition of thinking that has characterized both poles of the idealist-empiricist debate throughout history. It is, according to Bergson, an inevitable feature of our attempt to conceptualize temporal experience.

But that shouldn't make us give up trying. With that quixotic hope, one alternative for a more temporal way of understanding meaning making in organizations would involve a recognition of the narrative mode of cognition. But at present, the narrative mode is systematically undervalued and even suppressed. Narrative is mere anecdote. When it is studied, it is often spatialized as an object (Boje 1991). So at this point I can only ask for giving more attention to the narrative mode without knowing exactly how to do so. A key question is: can we develop more temporal methods for representing and analyzing organizational phenomena? This suggests the need to design techiniques of representation and vocabularies for analysis that, like narrative, appreciate experience as it unfolds, that are sensitive to rhythm, tempo and construction in the flow of becoming.

There are others who sense a similar need to incorporate a temporal dynamic in their work, and Fred Collopy, a colleague of mine at the Weatherhead School, is studying some of them for insights into the design of temporal representations. These include the early modern artists, such as Kandinsky and Klee, who sought for ways to give their paintings the dynamic power of music. These also include avant guard artists such as Morgan Russell and Stanton MacDonald-Wright, who worked on the design of musiclike instruments for playing visual images. In today's television and movies, we can see numerous examples of a movement toward dynamic visual representations-from computer graphics and computer animation to the daily weather reports. Without knowing exactly. how to do it, I suggest that we would benefit from developing tools for representation in organization studies that are dynamic, multi-sensory, evocative, open and tentative: tools that could create representations that are experienced with a sense of organizational duration as the interpenetration of past, present and future.

In organizational studies, some examples of work that open up the narrative mode of cognition and a more thoroughly temporal way of appreciating. meaning making are found in the study of discourse. Deidre Boden, in The Business of Talk (1994), for 
instance, uses Garfinkel and ethnomethodology to understand how organizational actors in their micro-level "structures of practical action" talk selves and organizations into being "under pressing conditions of time and space" (p. 18):

What is done now must make sense immediately, retrospectively, and to a consequential degree, in the future....as social actors discover from within the local logics of their actions, they reflexively...locate these activities within a stream of events that, taken together, constitute the rational production of the organization. [p. 198]

Boden, along with others in the discursive tradition, including Harre, Bilmes, Potter and Edwards, are giving us ways of approaching meaning and decision in organization as a lived experience, a duree, to be appreciated as a temporal whole.

Whether we think of the alternative to the information processing mode as a narrative mode of cognition, a discursive psychology, a dramaturgical analysis or an ethnomethodological analysis, the important thing is to appreciate that "Temporal change is the basic medium of all activity" (Waddington 1977). For understanding meaning making and decision, this temporal perspective highlights that context develops as action proceeds. Context is never simply available to resolve meanings in a problem space or to frame action with a branching model in an information processing sense.

We can imagine that actors have problem spaces and we can use information processing models to the extent that they prove handy while imagining things to be that way, but spatializing experience should not be allowed to suppress our search for other, more temporal ways of understanding organizational life. Actors as narrativizers of their own ongoing experience construct self and other as intentional, causal agents; read situations as they unfold; live in moments of tension that are only periodically and temporarily resolved; and struggle to recognize and repair breeches of canonicality. They are improvisational constructions of memory, meaning and action and it is that temporal medium of organizational life that we are at risk of losing as the spatialization of our knowledge about organization and cognition proceeds.

The objective is not to replace information processing modes of analysis, but, in the spirit of Rorty $(1979,1982)$, to make room for a temporal, narrative voice in hopes of keeping the conversation open and interesting. I hope together we can discuss possibilities for inventing tools of representation and vocabularies of analysis that might build a viable temporal presence in organizational studies.

\section{References}

Argyris, C. "Management Information Systems: The Challenge to Rationality and Emotionality," Management Science, 1971, pp. B275-292.

Bartlett, F. C. Remembering: A Study in Experimental and Social Psychology. Cambridge, England: Cambridge University Press, 1932.

Berger, P. L., and Luckman, T. The Social Construction of Reality: A Treatise in the Sociology of Knowledge. Garden City, NJ: Anchor, 1967.

Bergson, H. Matter and Memory, tr. N. M. Paul and W. S. Palmer. London: George Allen \& Unwin Ltd., 1911.

Bergson, H. Creative Evolution, tr. by Arthur Mitchell. London: Macmillan \& Co. Ltd., 1920. 
Blumer, H. Symbolic Interactionism: Perspective and Method. Englewood Cliffs, NJ: Prentice-Hall Inc., 1969.

Boden, D. The Business of Talk: Organizations in Action. Cambridge: Polity Press, 1994.

Boje, D. M. "The Storytelling Organization: A Study of Story Performance in an Office-Supply Firm,” Administrative Science Quarterly, 1991, pp. 106-126.

Boland, R. J. "The Process and Product of System Design," Management Science (24:9), 1978, pp. 887-898.

Boland, R. J. "Control Causality and Information System Requirements," Accounting, Organizations and Society (4:4), 1979, pp. 259-272.

Boland, R. J. "Sense-Making of Accounting Data as a Technique of Organizational Diagnosis," Management Science (30:7), 1984, pp. 868-882.

Boland, R. J. "Accounting and the Interpretive Act," Accounting, Organizations and Society (18:2/3), 1993, pp. 125-146.

Boland, R. J., and Greenberg, R. "Method and Metaphor in Organizational Analysis," Accounting, Management and Information Technologies (2:2), 1992, pp. 117-141.

Boland, R. J.; Greenberg, R. H.; Park, S. H.; and Han, I. "Mapping the Process of Problem Reformulation: Implications for Understanding Strategic Thought," in Mapping Strategic Thought, A. Huff (ed.). Chichester: John Wiley, 1990, pp. 195-226.

Boland, R. J., and Pondy, L. R. "Accounting in Organizations: Toward a Union of Rational and Natural Perspectives," Accounting, Organizations and Society (8:2/3), 1983, pp. 223-234.

Boland, R. J., and Pondy, L. R. "Micro Dynamics of a Budget Cutting Process: Modes, Models and Structure," Accounting, Organizations and Society (11:4/5), 1986, pp. 403-422.

Boland, R. J., and Schultze, U. "Narrating Accountability" in Accountability: Power, Ethos and the Technologies of Managing, R. Munro and J. Mouritsen (eds.). London: Thompson Press, 1996, pp. 62-81.

Boland, R. J.; Schwartz, D.; and Tenkasi, R. "Sharing Perspectives in Distributed Decision Making," Association of Computing Machinery, Conference on Computer Supported Cooperative Work, Toronto, 1992.

Boland, R. J.. and Tenkasi, R. V. "Perspective Making and Perspective Taking in Communities of Knowing," Organization Science, August 1995, pp. 350-372.

Boland, R. J.; Tenkasi, R. V.; and D. Te'eni "Designing Information Technology to Support Distributed Cognition," Organization Science (5:3), 1994, pp. 456-475.

Bruner, J. Actual Minds, Possible Worlds. Cambridge, MA: Harvard University Press, 1986.

Bruner, J. Acts of Meaning. Cambridge, MA: Harvard University Press, 1990.

Churchman, C. W., and Schainblatt, A. H. "The Researcher and the Manager: A Dialectic of Implementation," Management Science (11:4), 1965, pp. B69-B73.

Gilligan, C. In a Different Voice: Psychological Theory and Women's Development. Cambridge, MA: Harvard University Press, 1982.

Kang, Y. A. Schema and Symbol: A Study in Kant's Doctrine of Schematism. Amsterdam: Free University Press, 1985.

Kant, I. Critique of Pure Reason, tr. N. K. Smith. New York: St Martins Press, 1965 (1 ${ }^{\text {st }}$ ed., $1781,2^{\text {nd }}$ ed., 1787).

Kelley, H. H. "The Process of Causal Attribution," American Psychologist, February 1973, pp. 107-128.

Lakoff, G., and Johnson, M. Metaphors We Live By. Chicago: University of Chicago Press, 1980.

Leibniz, G. W. New Essays on Human Understanding, tr. \& ed. Peter Remnant and Jonathon Bennett. Cambridge, England: Cambridge University Press, 1981 (1765).

Locke, J. An Essay Concerning Human Understanding, Peter H. Nidditch (ed.). Oxford: Oxford University Press, 1975 (Based on $4^{\text {th }}$ ed., 1700, $1^{\text {st }}$ ed., 1690).

Macintosh, N. B., and Scapens, R. W. "Structuration Theory in Management Accounting," Accounting, Organizations and Society, 1990, pp. 455-477. 
Merleau-Ponty, M. The Prose of the World. Claude LeFort (ed.). Evanston, IL: Northwestern University Press, 1973.

Meyer, A. D. "Mingling Decision Making Metaphors," Academy of Management Review, 1984, pp. 6-17.

Milne, R. Budget Slack, unpublished Ph.D. dissertation, University of Illinois at UrbanaChampaign, 1981.

Morgan, G. Images of Organizations. Beverly Hills, CA: Sage Publications, 1986.

Rorty, R. Philosophy and the Mirror of Nature. Princeton, NJ: Princeton University Press, 1979.

Rorty, R. Consequences of Pragmatism. Minneapolis: University of Minnesota Press, 1982.

Schön, D. "Generative Metaphor: A Perspective on Problem Setting in Social Policy," in Metaphor and Thought, A. Ortony (ed.). Cambridge, England: Cambridge University Press, 1979, pp. 254-283.

Scott, W. R. "Developments in Organization Theory, 1960-1980," American Behavioral Scientist, 1981, pp. 407-422.

Simon, H. A. Models of Thought. New Haven, CT: Yale University Press, 1979.

Simon, H. A. The Sciences of the Artificial, $3^{\text {rd }}$ ed. Cambridge, MA: MIT Press, 1996.

Sperber, D. Rethinking Symbolism. Cambridge, England: Cambridge University Press, 1974.

Te'eni, D.; Schwartz, D.; and Boland, R. J. "Cognitive Maps for Communication: Specifying Functionality and Usability," Fourth Symposium on Human Factors in Information Systems, Phoenix, AZ, 1992.

Waddington, C. H. Tools for Thought. London: Jonathan Cape, 1977.

Weick, K. The Social Psychology of Organizing, $2^{\text {nd }}$ ed. Reading, MA: Addison-Wesley, 1979.

Wittgenstein, L. Tracttatus Logico Philosophicus, tr. D. F. Pears and B. F. McGuinnes. London: Routledge \& Kegan Paul, 1961 (1921).

Wittgenstein, L. Philosophical Investigations, tr. G. E. M. Anscombe. Oxford: Basil Blackwell, 1974 (1956).

\section{About the Author}

Richard J. Boland, Jr. is Professor and Chair of the Department of Information Systems at the Weatherhead School of Management at Case Western Reserve University. Previously he was Professor of Accountancy at the University of Illinois at Urbana-Champaign. He has held a number of visiting positions, including the Eric Malmsten Professorship at the University of Gothenburg in Sweden in 1988-89, and the Arthur Andersen Distinguished Visiting Fellow at the Judge Institute of Management Studies at the University of Cambridge in 1995. His major area of research is the qualitative study of the design and use of information systems. Recent papers have concerned sense making in distributed cognition, hermeneutics applied to organizational texts, and narrative as a mode of cognition. Professor Boland is Editor-in-Chief of the research journal Accounting, Management and Information Technologies, and co-editor of the Wiley Series in Information Systems. He serves on the editorial board of six journals, including Information.Systems Research and Accounting, Organizations and Society. 